\title{
Single fibre electromyography in central core disease
}

\author{
A. CRUZ MART ÍNEZ, M. T. FERRER, J. M. L Ó P EZ - T E R R A D A , \\ I. PA S C U A L - C A STROVIEJO, A N D P. MINGO \\ From Servicio Central de Neurofisiología Clínica, Sección de EMG, Ciudad Sanitaria La Paz, \\ Madrid, Spain
}

SUMMARY Single fibre electromyography in the extensor digitorum communis muscle was studied in five patients with central core disease. The average number of muscle fibre action potentials belonging to the same motor unit was higher in patients than in healthy subjects of the same age. The increase in motor unit fibre density is consistent with increased terminal innervation ratio described in other papers about central core disease.

Central core disease was first described by Shy and Magee (1956) in five patients of the same family. Hypotonia, non-progressive myopathy with proximal weakness, occasionally facial impairment, and skeletal deformities such as congenital hip dislocation, pes cavus, and kyphoscoliosis, are the main clinical manifestations. Cases without muscular weakness and with only pes cavus have also been described (Telerman-Toppet et al., 1973).

Electromyographic study has been described as normal, myopathic (Mrozeck et al., 1970), or neurogenic with polyphasic potentials of long duration and increased voltage (Isaacs et al., 1975). Nerve conduction velocities are normal (Isaacs $e t$ al., 1975; Bethlem, 1977) or slowed (Hooshmand et al., 1971).

The results of the electromyographic and recent muscle biopsy studies (Telerman-Toppet et al., 1973; Isaacs et al., 1975; Cöers et al., 1976) indicate a neurogenic basis for the disease (Engel and Warmolts, 1973; Telerman-Toppet et al., 1973; Isaacs et al., 1975; Bethlem, 1977).

In this paper we present the results of single fibre electromyographic study in five patients with central core disease.

\section{Method}

Single fibre EMG was performed according to the technique described by Ekstedt (1964), Ekstedt and Stålberg (1973), and Stålberg and Ekstedt (1973).

Medelec MS6 equipment was used. A special

Address for correspondence and reprint requests: Dr A. Cruz Martínez Sta. Casilda $1,6^{\circ}$, E. Madrid 5, Spain.

Accepted 30 January 1979 electrode (Medelec SF25) with a recording area of $25 \mu \mathrm{m}$ diameter was inserted into the right extensor digitorum communis muscle (EDC) during slight voluntary contraction. A delay line of $20 \mathrm{~ms}$ and a low frequency limit of $500 \mathrm{~Hz}$ were used to reduce activity recorded from distant fibres. Action potentials were recorded on a photosensitive film and displayed on a storage oscilloscope.

The fibre density of the motor unit was studied according to the technique of Stålberg and Thiele? (1975), determining the average number of muscle fibres belonging to the same motor unit with action potential exceeding $200 \mu \mathrm{V}$ and within the uptake area of the electrode. The average number was calculated for 20 random and different electrode positions.

The jitter interval of the double or complex potentials was calculated manually (Ekstedt $e t$ al., 1974) from superimposed recording. Mean range of five (MR5) or ten (MR10) was measured and the conversion factor ( 0.49 or 0.37 respectively) applied to calculate the mean consecutive differences (MCD) of the interpotential interval values. In normal subjects MCD varies between 5 and $50 \mu \mathrm{S}$ (Ekstedt et al., 1974).

\section{Subjects}

Three males and two females, belonging to two families and aged 13 to 43 years (mean age 22 years), were investigated (Table 1). The diagnosis of central core disease was based on the findings of muscle biopsy. Cases 1, 2, and 3 were siblings. Case 5 was the father of case 4 (Table 1).

The main clinical features of the patients are 
Table 1 Main features in five patients with central core disease. Cases 1, 2, and 3 are siblings. Cases 4 (son) and 5 (father) belong to another family

\begin{tabular}{|c|c|c|c|c|c|c|c|c|}
\hline Case & $\begin{array}{l}\text { Age } \\
(y r)\end{array}$ & Sex & $\begin{array}{l}\text { Delayed } \\
\text { motor } \\
\text { development }\end{array}$ & $\begin{array}{l}\text { Facial } \\
\text { weakness }\end{array}$ & $\begin{array}{l}\text { Proximal } \\
\text { weakness }\end{array}$ & $\begin{array}{l}\text { Distal } \\
\text { weakness } \\
\text { lower limbs }\end{array}$ & $\begin{array}{l}\text { Tendon } \\
\text { jerks }\end{array}$ & Deformities \\
\hline 1 & 14 & $\mathbf{M}$ & + & + & + & + & $\downarrow$ & Pes cavus \\
\hline 2 & 17 & $\mathbf{F}$ & + & + & ++ & + & $\downarrow$ & Pes cavus \\
\hline 3 & 24 & $\mathbf{F}$ & + & + & +++ & + & $\downarrow$ & Pes cavus \\
\hline 4 & 13 & $\mathbf{M}$ & + & - & + & - & $\downarrow$ & Kyphoscoliosis \\
\hline 5 & 43 & $\mathbf{F}$ & $?$ & - & + & - & $\downarrow$ & - \\
\hline
\end{tabular}

shown in Table 1. All the cases had hypotonia and delay in motor milestones during infancy.

The muscle biopsy samples showed the typical findings described in this disease. One or several cores were seen in the centre of the muscle fibres. The cores were present only in the type 1 fibres, except in case 2 where they were also present in a few type 2 fibres. The proportion of type 1 fibres with cores varied from $15 \%$ (case 4) to $100 \%$ (case 1). A normal mosaic of type 1 and 2 fibres was seen in case 4 . The other patients showed a type 1 fibre predominance. In case $5,90 \%$ of the fibres were of type 1 . Splitting of the fibres was also observed.

The control group consisted of 20 healthy subjects, 11 males and nine females, aged from 8 to 43 years (mean age 21 years). All the control subjects had no history, signs, or symptoms of neuromuscular diseases. Clinical examination was normal.

\section{Results}

The mean value of the motor unit fibre density in EDC was 1.51 fibres per recording area $(\mathrm{SD}=$ $0.091 ; \mathrm{SE}=0.02$ ) in control subjects (range: 1.351.65) (Fig. 1).
The jitter in the control group was calculated from 92 potentials. The mean value of the MCD was $29.3 \mu \mathrm{S}(\mathrm{SD}=10.38 ; \mathrm{SE}=1.09)$ with a range from 9.2 to $53.6 \mu \mathrm{s}$. Only three measurements were over $50 \mu \mathrm{s}(51.8,51.8$, and $53.6 \mu \mathrm{s})$ (Fig. 2).

In normal subjects, single muscle fibre potentials were recorded in $55.3 \%$ of the random electrode insertions. In $38.3 \%$ of the points, potentials from two fibres were registered. Only in $6.3 \%$ of the insertions were potentials belonging to three or four fibres of the same motor unit observed (Fig. 3).

The mean value of the motor unit fibre density in five patients with central core disease was 2.22 fibres per recording area. Individual values are shown in Table 2 and Fig. 1. All the values are above the normal limits for healthy subjects.

In central core disease the jitter was measured in 31 complex potentials. The mean value of the MCD was $28.6 \mu \mathrm{s}$, with a range from 9.2 to $48.1 \mu$ s (Figs. 2 and 4). All the values are within the normal limits for healthy subjects of the same age. No impulse blocking was observed. The highest values of the jitter usually correspond to late components of a complex potential with three, four or more fibres.

In central core disease single potentials were

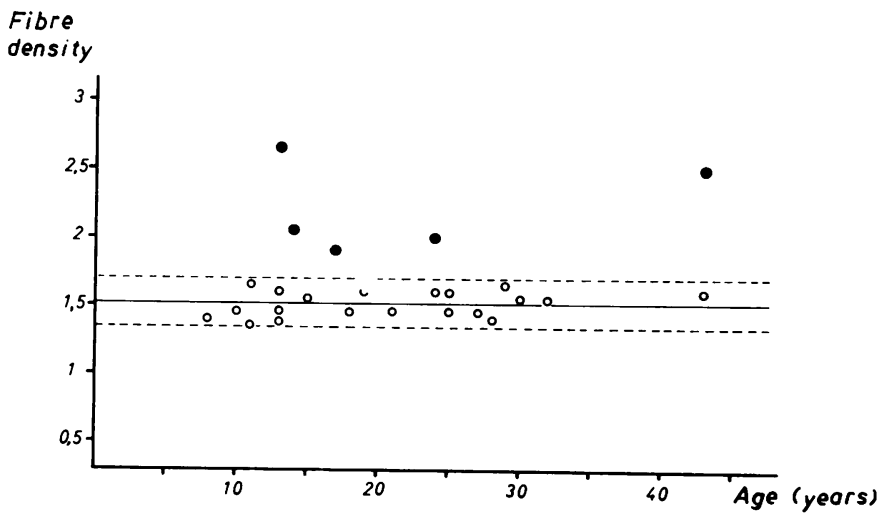

Fig. 1 Fibre density mean value (full line) and two standard deviations above and below the mean (interrupted lines) in control subjects $(O)$ (20 healthy subjects, 8-43 years, mean age 21 years), and patients with central core disease (0) (five patients, aged 13-43 years, mean age 22 years). Mean value in control subjects $=1.51 \pm 0.091$, and in patients with central core disease $=2.22$. 
$M C D$

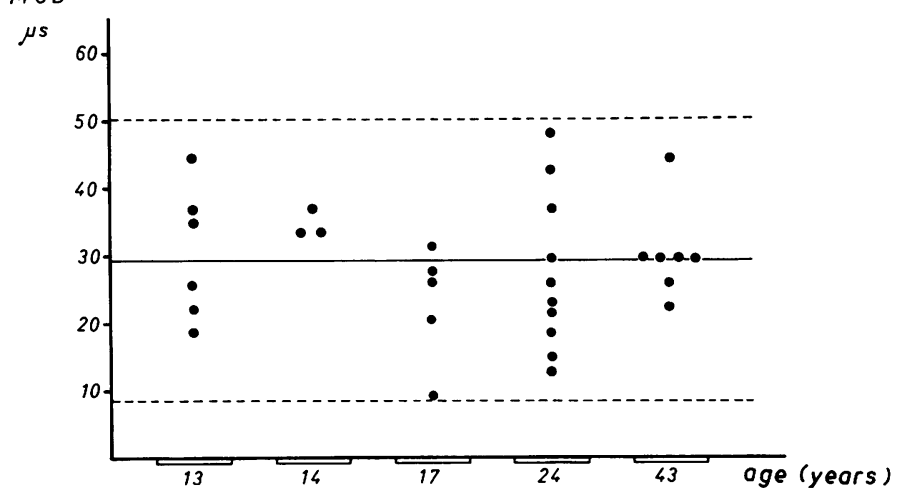

Fig. 2 Jitter. MCD values. Mean value in control subjects (92 potentials): $29.3 \mu \mathrm{s}$. \pm 10.38 . Mean value in central core disease (31 potentials): $28.6 \mu \mathrm{s}$. $\bullet=$ individual values in central core disease. Full line indicates mean value in control subjects, and interrupted lines two standard deviations above and below the mean.

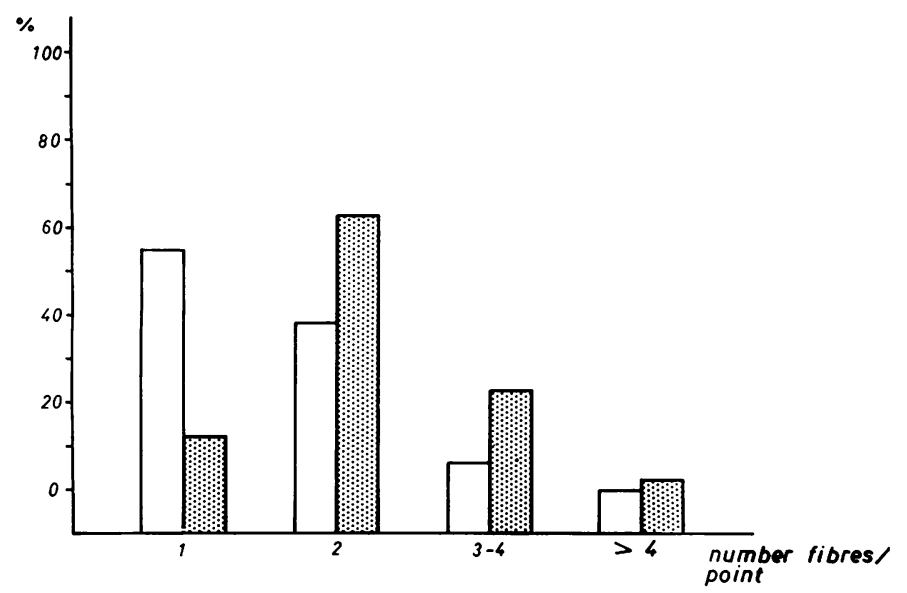

Fig. 3 Percentage of random electrode insertions in which potentials from one, two, three, four, or more fibres are registered. $\square=$ control subjects, $\mathbb{Z}=$ patients with central core disease.

Table 2 Fibre density of the motor unit and terminal innervation ratio in different reports. The results of the present study are included under fibre density in central core disease

\begin{tabular}{|c|c|c|c|}
\hline Disease & $\begin{array}{l}\text { Terminal } \\
\text { innervation } \\
\text { ratio* }\end{array}$ & $\begin{array}{l}\text { Fibre } \\
\text { density }\end{array}$ & References \\
\hline $\begin{array}{l}\text { Amyotrophic } \\
\text { lateral sclerosis }\end{array}$ & 1.80 & 3.3 & \\
\hline Syringomyelia & 2.11 & 4.7 & $\begin{array}{l}\text { Cöers et al., 1973b; Cöers and } \\
\text { Telerman-Toppet, 1977; }\end{array}$ \\
\hline $\begin{array}{l}\text { Progressive } \\
\text { spinal muscular } \\
\text { atrophy }\end{array}$ & 2.27 & 5.3 & Stålberg et al., 1975 \\
\hline $\begin{array}{l}\text { Duchenne } \\
\text { dystrophy }\end{array}$ & 1.12 & 3.1 & $\begin{array}{l}\text { Cöers and Telerman-Toppet, } \\
\text { 1977; Stålberg and Eksted, } \\
1973\end{array}$ \\
\hline $\begin{array}{l}\text { Central } \\
\text { core disease }\end{array}$ & $\begin{array}{l}1.32 \\
1.43\end{array}$ & $\begin{array}{l}2.05 \\
1.90 \\
2.00 \\
2.65 \\
2.50\end{array}$ & $\begin{array}{l}\text { Isaacs et al., } 1975 \\
\text { Cöers et al., } 1976\end{array}$ \\
\hline
\end{tabular}

*Normal $=1.1 \pm 0.05$ (Cöers et al., 1973a). recorded only at $6 \%$ of the points. Potentials belonging to two fibres (63\% of points), to three or four fibres $(23 \%)$, and multiple potentials with more of four fibres $(2 \%)$ were more frequent than in control subjects (Fig. 3).

\section{Discussion}

The patients in this series had clinical features and morphological changes consistent with central core disease. Results of clinical and morphological studies in three of these cases and conventional EMG in the same patients have been published previously (Pascual Castroviejo et al., 1974; LópezTerradas, and Conde, 1979).

Single fibre EMG can provide information about the pathology of the motor unit when no definite signs of abnormality are found in the conventional EMG. We could not find any reported results of this technique applied to the congenital myopathies. 


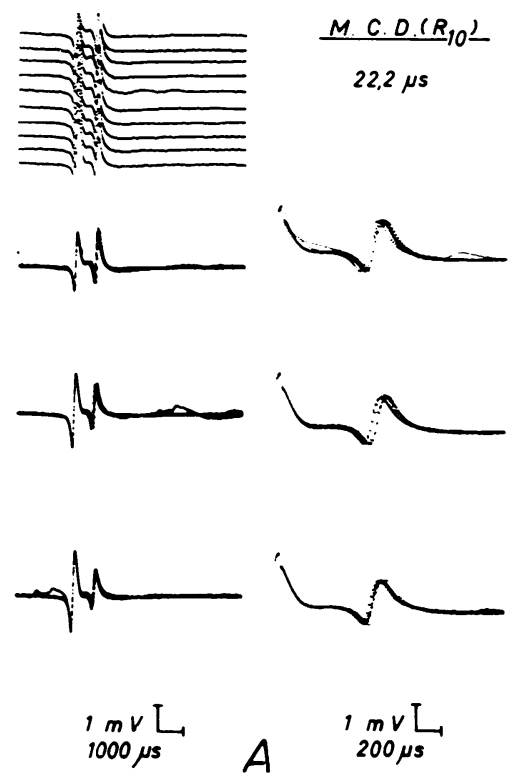

The average of the motor unit fibre density per recording area of the electrode and the values of the MCD in our normal subjects are similar to those published by Stålberg and Thiele (1975) and Ekstedt et al. (1974).

Our patients with central core disease showed an increase in the values of the motor unit fibre density when we compared them with healthy subjects of the same age. Double and complex potentials with three, four, or more fibres belonging to the same motor unit were more frequent in central core disease than in normal subjects. The jitter was only measured in some potentials, with normal results. High but normal jitter (near $50 \mu \mathrm{s}$ ) was observed in late components of some complex potentials. These values suggest that patients with central core disease have, in general, stable neuromuscular transmission.

Motor unit fibre density increases in different diseases. The highest values are observed in lower motor neurone disorders, such as amyotrophic lateral sclerosis, progressive spinal muscular atrophy, and syringomyelia (Stålberg et al., 1975), but density is also high in myopathies, especially in Duchenne muscular dystrophy (Stålberg and Ekstedt, 1973). Increased fibre density indicates that the muscle fibres belonging to the same motor unit are increased per recording area of the electrode. It is usually the result of reinnervation and, in the EMG, generally corresponds to polyphasic and high amplitude action potentials and, possibly, to late components of the motor unit

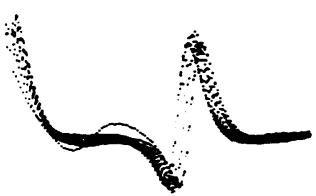

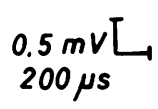

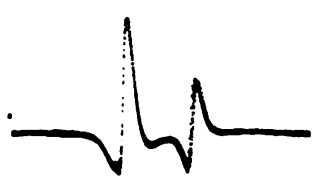

$B \quad \operatorname{mov}_{500 \mathrm{~s}}$
Fig. 4 Normal jitter in two potential pairs in central core disease. $(A) 24$ years $M C D$ $(R 10)=22.2 \mu s(B) 43$ years $\operatorname{MCD}(R 10)=29.6 \mu \mathrm{s}$. Potentials are registered at two different sweeps. In $A$ (right) and B (top), only the second potential of the pair is seen. potentials. These late components are the result of collateral sprouting with reinnervation of previously denervated muscle fibres (Borenstein and Desmedt, 1973). In the first phases of reinnervation, late components have an increased jitter and intermittent blocking. Afterwards, the neuromuscular transmission is more secure and the late components have a fixed latency (Borenstein and Desmedt, 1973). This theory is consistent with the results of single fibre EMG. (Stålberg et al., 1975).

In our patients, increased motor unit fibre density was accompanied by an increased percentage $(7 \%$ to $20 \%)$ of motor unit potentials with late components (López-Terradas and Conde, 1979). In normal subjects, only a maximum of $3 \%$ of the motor unit potentials show late components at 9-16 ms from the main component (NissenPetersen et al., 1969).

Increased motor unit fibre density and motor unit potentials with late components are a striking feature in myopathies, especially in Duchenne dystrophy (Stålberg and Ekstedt, 1973; Stålberg et al., 1974; Desmedt and Borenstein, 1973; 1976). Desmedt and Borenstein suggest that collateral innervation is also present in muscular dystrophy.

Study of the terminal innervation ratio (Cöers and Woolf, 1959; Cöers et al., 1973a) shows that in normal subjects the mean is 1.1 . In neurogenic atrophy the terminal innervation ratio is increased (Cöers et al., 1973b), indicating an increased amount of branching. Although the motor unit fibre density is also increased in Duchenne dys- 
trophy, the terminal innervation ratio is normal in this disease (Cöers and Telerman-Toppet, 1977). Obviously, increased peripheral branching is not the only cause of increment in the fibre density of the motor unit. In Duchenne dystrophy, it is observed that small clusters of regenerating muscle fibres receive innervation (Swash and Schwartz, 1977), split fibres (Aloisi et al., 1974; Schwartz et al., 1976), and a separate part of a fibre divided by segmental necrosis, which develops extrajunctional acetylcholine receptors (Katz and Miledi, 1964) and receives new innervation from unemployed axons (Cöers and Telermann-Toppet, 1977), can explain late components of the motor unit potentials and increased fibre density of the motor unit without an increased terminal innervation ratio.

In central core disease necrosis of the fibres is not a striking feature, whereas increased terminal innervation ratio was found by Isaacs et al. (1975) and Cöers et al. (1976). The increased motor unit fibre density in central core disease is less than the values observed in progressive diseases of the lower motor neurone (Table 2), but similar to those described in mild or moderately severe axonal neuropathies (Thiele and Stålberg, 1975). Increased terminal innervation ratio is well correlated with increased fibre density of the motor unit in lower motor neurone diseases (Stålberg $e t$ al., 1975), and other processes such as in psychotic patients (Crayton et al., 1977). In our series of cases of central core disease, the average value of the motor unit fibre density was increased by $46 \%$, and the terminal innervation ratio was increased by $20-30 \%$ in the cases of Isaacs et al. (1975) and Cöers et al. (1976).

We think that the single fibre EMG study in our patients provides information about the motor unit in central core disease. We have previously commented that the EMG in central core disease is contradictory, since both myogenic and neurogenic changes are described (Mrozeck et al., 1970; Hooshmand et al., 1971; Isaacs et al., 1975). Motor unit fibre density and terminal innervation ratio are consistent with a possible neural aetiology of the disease (Engel and Warmolts, 1973; Bethlem, 1977), since an increment of both parameters is only described in neuropathies. The process affects type 2 fibres, which disappear progressively and possibly suffer a transformation from type 2 to type 1 with predominance and cores in the latter (Telerman-Toppet et al., 1973). Reinnervation of type 2 by type 1 fibres could explain the disappearance of type 2 fibres with the predominance of type 1 (Teleman-Toppet et al., 1973), the collateral branching with increased terminal innervation ratio (Isaacs et al., 1975; Cöers et al., 1976), the increased percentage of late components of the motor unit potentials, and the increment in motor unit fibre density.

\section{References}

Aloisi, M., Pierobon Bermiolo, S., and Schiaffino, S. (1974). In Structure and Function of Normal and Diseased Muscle and Peripheral Nerve. Edited by I. Hausmanowa-Petrusewicz and H. Jedrejowska. Polish Medical Publishers: Warsaw.

Bethlem, J. (1977). Myopathies, North-Holland: Amsterdam.

Borenstein, S., and Desmedt, J. E. (1973). Electromyographical signs of collateral reinnervation. In New Developments in Electromyography and Clinical Neurophysiology, vol. 1, 130-140. Edited by J. E. Desmedt. Karger: Basel.

Cöers, C., and Woolf, A. L. (1959). The Innervation of Muscle: A Biopsy Study. Blackwell: Oxford.

Cöers, C., Telerman-Toppet, N., and Gérard, J. M. (1973a). Terminal innervation ratio in neuromuscular disease. 1. Methods and controls. Archives of Neurology (Chicago), 29, 210-214.

Cöers, C., Telerman-Toppet, N., and Gérard, J. M. (1973b). Terminal innervation ratio in neuro-o muscular diseases. 2. Disorders of lower motor neuron, peripheral nerve, muscle. Archives of Neurology (Chicago), 29, 215-222.

Cöers, C., Telerman-Toppet, N., Gérard, J. M.फ़े Szliwowski, H., Bethlem, J., and Wijngaarlen G. K. V. (1976). Changes in motor innervation and histochemical pattern of muscle fibres in some congenital myopathies. Neurology (Minneapolis), 26, 1046-1053.

Cöers, C., and Telerman-Toppet, N. (1977). Morphological changes of motor units in Duchenne's muscular dystrophy. Archives of Neurology (Chicago), 34, $296-402$.

Crayton, J. W., Stålberg, E., and Hilton-Brown, P. (1977). The motor unit in psychotic patients: a single fibre EMG study. Journal of Neurology, Neurosurgery, and Psychiatry, 40, 455-463.

Desmedt, J. E., and Borenstein, S. (1973). Collateral innervation of muscle fibres by motor axons of dystrophic motor units. Nature, 264, 500-501.

Desmedt, J. E., and Borenstein, S. (1976). Regeneration in Duchenne dystrophy. Archives of Neurology (Chicago), 33, 642-650.

Ekstedt, J. (1964). Human single muscle fibre action potentials. Acta Physiologica Scandinavica, 61, Supplement 226, 1-96.

Ekstedt, J., and Stålberg, E. (1973). Single fibre electromyography for the study of the microphysiology of the human muscle. In New Developments in Electromyography and Clinical Neurophysiology, vol. 1, pp. 89-112. Edited by J. E. Desmedt. Karger: Basel. 
Ekstedt, J., Nilsson, G., and Stålberg, E. (1974). Calculation of the electromyographic jitter. Journal of Neurology, Neurosurgery, and Psychiatry, 37, 526-539.

Engel, W. K., and Warmolts, J. R. (1973). The motor unit. Diseases affecting it in toto or in portio. In New Developments in Electromyography and Clinical Neurophysiology, vol. 1, pp. 141-177. Edited by J. E. Desmedt. Karger: Basel.

Hooshmand, H., Martínez, A. J., and Rosenblum, W. I. (1971). Arthrogryposis multiplex congenita. Simultaneous involvement of peripheral nerve and skeletal muscle. Archives of Neurology (Chicago), 24, 561-572.

Isaacs, H., Heffron, J. J. A., and Badenhorst, M. (1975). Central core disease: a correlated genetic, histochemical, ultramicroscopic, and biochemical study. Journal of Neurology, Neurosurgery, and Psychiatry, 38, 1177-1186.

Katz, H., and Miledi, R. (1964). The development of acetylcholine sensitivity in nerve-free segments of skeletal muscle. Journal of Physiology, 170, 389-396.

López-Terradas, J. M., and Conde Lopez, M. (1979). Late components of motor unit potentials in central core disease. Journal of Neurology, Neurosurgery, and Psychiatry, 42, 461-464.

Mrozek, K., Strugalska, M., and Fidzianska, A. (1970). A sporadic case of central core disease. Journal of the Neurological Sciences, 10, 339-348.

Nissen-Petersen, H., Guld, C., and Buchthal, F. (1969). A delay line to record random action potentials. Electroencephalography and Clinical Neurophysiology, 26, 100-106.

Pascual Castroviejo, I., Gutiérrez, M., Rodríguez Costa, T., López, M. V., Ricoy, J. M., and Morales, M. C. (1974). Central core disease: presentación de 4 casos y revisión de la literatura. Anales Españoles de Pediatria, 7, 524-536.

Schwartz, M. S., Sergenat, M. K., and Swash, M.
(1976). Longitudinal fibre splitting in neurogenic muscular disorders: its relation to the pathogenesis of myopathic change. Brain, 99, 617-636.

Shy, G. M., and Magee, K. R. (1956). A new congenital non-progressive myopathy. Brain, 79, 610 621.

Stålberg, E., and Ekstedt, J. (1973). Single fibre EMG and microphysiology of the motor unit in normal and diseased muscle. In New Developments in Electromyography and Clinical Neurophysiology, vol. 1, pp. 113-179. Edited by J. E. Desmedt. Karger: Basel.

Stålberg, E., Trontelj, J. V., and Janko, M. (1974). Single fibre EMG findings in muscular dystrophy. In Structure and Function of Normal and Diseased Muscle and Peripheral Nerve, pp. 185-190. Edited by I. Hausmanowa-Petrusewicz and $\mathrm{H}$. Jedrejowska. Polish Medical Publishers: Warsaw.

Stålberg, E., and Thiele, B. (1975). Motor unit fibre density in the extensor digitorum communis muscle. Single fibre EMG study in normal subjects at different ages. Journal of Neurology, Neurosurgery, and Psychiatry, 38, 874-880.

Stålberg, E., Schwartz, M. S., and Trontelj, J. V. (1975). Single fibre electromyography in various processes affecting the anterior horn cell. Journal of the Neurological Sciences, 24, 403-415.

Swash, M., and Schwartz, M. S. (1977). Implications of longitudinal muscle fibre splitting in neurogenic and myopathic disorders. Journal of Neurology, Neurosurgery, and Psychiatry, 40, 1125-1159.

Telerman-Toppet, N., Gérard, J. M., and Cöers, C. (1973). Central core disease: a study of clinically unaffected muscle. Journal of the Neurological Sciences, 19, 207-223.

Thiele, B., and Stålberg, E. (1975). Single fibre EMG findings in polyneuropathies of different aetiology. Journal of Neurology, Neurosurgery, and Psychiatry, 38, 881-887. 